\title{
O MUSEU DE ZOOLOGIA COMO ESPAÇO FORMATIVO: UMA EXPERIÊNCIA QUE VALE A PENA SER VIVENCIADA
}

\author{
Lucas Henrique dos Santos ${ }^{1}$ \\ http://orcid.org/0000-0002-5850-0089 \\ Fernando Jerep 2 \\ http://orcid.org/0000-0003-3561-6887 \\ Adriana Regina de Jesus Santos ${ }^{3}$ \\ Dhttp://orcid.org/0000-0002-9346-5311
}

Resumo: 0 presente artigo tem como objetivos: a) compreender a importância do Museu de Zoologia enquanto espaço formativo, e b) identificar como o museu de Zoologia pode auxiliar no processo de ensino e aprendizagem de alunos dos anos finais do ensino fundamental de uma escola pública localizada na cidade de Londrina, acerca dos conceitos de conservação ambiental e biodiversidade, tendo como parâmetro, os animais taxidermizados. Utilizamos como metodologia a pesquisa bibliográfica e de campo. Ao término da pesquisa constatou-se que os alunos se apropriaram acerca do conceito e do contexto que envolve os animais taxidermizados, bem como, a necessidade de perceber a importância da relação entre o homem e a natureza no que tange a preservação do meio ambiente.

Palavras-chave: Museu de zoologia. Educação ambiental. Taxidermia.

1 Graduado em Ciencias Biologicas na Universidade Norte do Parana. Especialização em Ensino de Ciencias e Biologia da Universidade Estadual de Londrina. Mestrando no Programa de PósGraduação em Ciencias Biologicas da Universidade Estadual de Londrina. Bolsista Capes. E-mail: lucas.henriquebio@outlook.com.

2 Graduado em licenciatura e bacharelado em Ciências Biológicas e mestre em Ciências Biológicas (ac Zoologia) pela Universidade Estadual de Londrina (2006). Doutorado em Zoologia pela PUCRS, Pós doutor pelo NMNH. Atualmente é pesquisador e professor adjunto e Coordenador do Programa de Pós-Graduação em Ciencias Biologicas da Universidade Estadual de Londrina. E-mail: fjerep@gmail.com

3 Graduação em Pedagogia. Mestrado em Educação pela UEPG. Doutorado em Educação pela PUCSP. Pós-Doutorado em Educação pela UFF. Docente do Curso de Pedagogia e Coordenadora do Programa de Pós-Graduação em Educação pela Universidade Estadual de Londrina. E-mail: adrianar@uel.br 
THE ZOOLOGY MUSEUM AS A TEACHING SPACE: AN EXPERIENCE THAT IS WORTH BEING LIVED

Abstract: This article aims to: a) understand the importance of the Zoology Museum as a formative space, and b) identify how the Zoology Museum can assist in the process of teaching and learning of students from the final years of elementary school in a public school located in the city of Londrina, about the concepts of environmental conservation and biodiversity, having as parameter, the taxidermied animals. We used as methodology the bibliographic and field research. At the end of the research it was found that the students were able to know the concept and the context that involves the taxidermied animals, as well as the need to realize the importance of the relationship between man and nature regarding the preservation of the environment.

Keywords: Museum of zoology. Environmental education. Taxidermy.

\section{EL MUSEO DE ZOOLOGÍA COMO ESPACIO FORMATIVO: UNA EXPERIENCIA QUE VALE LA PENA VIVIR}

Resumen: Este artículo tiene como objetivo: a) comprender la importancia del Museo de Zoología como espacio formativo, y b) identificar cómo el Museo de Zoología puede ayudar en el proceso de enseñanza y aprendizaje de los estudiantes de los últimos años de la escuela primaria en una escuela pública ubicada en la ciudad de Londrina, sobre los conceptos de conservación del medio ambiente y la biodiversidad, teniendo como parámetro, los animales taxidermizados. Hemos utilizado como metodología la investigación bibliográfica y de campo. Al final de la investigación se observó que los alumnos conocieron el concepto y el contexto que envuelve a los animales taxidermizados, así como la necesidad de darse cuenta de la importancia de la relación entre el hombre y la naturaleza en cuanto a la preservación del medio ambiente.

Palabras clave: Museo de zoología. Educación ambiental. Taxidermia. 
O museu de zoologia como espaço formativo: uma experiência que vale a pena ser vivenciada

\section{Introdução}

As recentes tendências na pesquisa educacional sobre o museu como artefato cultural, social e tecnológico no auxílio do ensino de ciências e biologia têm dado destaque aos estudos sobre as imagens, significados e crenças que alunos e professores têm em relação à educação ambiental (VASCONCELOS; SOUTO, 2003). Apesar da diversidade teórica e conceitual, identificar e compreender as percepções desses sujeitos possuem sobre tal aspecto é o foco deste estudo, visando contribuir com o conjunto dos demais.

Isso posto, o referido artigo tem como objetivos: a) compreender a importância do Museu de Zoologia enquanto espaço formativo, e b) identificar como o museu de Zoologia pode auxiliar no processo de ensino e aprendizagem de alunos dos anos finais do ensino fundamental, acerca dos conceitos de conservação ambiental e biodiversidade, tendo como parâmetro, os animais taxidermizados.

Para tanto, utilizamos como metodologia a pesquisa bibliográfica e de campo, tendo com lócus o Museu de Zoologia da Universidade Estadual de Londrina.

Para uma melhor compreensão este artigo foi dividido da seguinte maneira: Em um primeiro momento buscamos abordar o conceito e o contexto do museu enquanto espaço formativo. No que se refere ao segundo momento, apresentaremos as ações desenvolvidas no Museu de Zoologia da Universidade Estadual de Londrina, junto aos alunos dos anos finais do ensino fundamental de uma escola pública da cidade de Londrina- PR e por fim, finalizaremos apresentando algumas reflexões e proposições acerca da temática, objeto do nosso estudo.

\section{Museu: breve histórico de conceitos e mudanças}

Desde sua origem, os museus passaram por modificações que alteraram o foco de sua atuação, transferindo o olhar e as práticas dos profissionais dessas instituições com o cuidado das suas coleções para a atenção com o público (FREIRE, 1992).

Segundo o ICOM (Comitê Internacional de Museus) na definição aprovada pela 20 a Assembleia Geral, os museus são definidos como uma: "Instituição permanente, sem fins lucrativos, a serviço da sociedade e do seu desenvolvimento, 
aberta ao público e que adquire, conserva, investiga, difunde e expõe os testemunhos materiais do homem e de seu entorno, para educação e deleite da sociedade" (MARANDINO, 2005, p. 168).

Vale ressaltar conforme Marandino (2008) que o uso de museus é uma percepção relativamente recente na história da educação, isto é, só a partir da metade do século XX estes espaços passaram a ser vistos como lugares educativos. A partir de então os museus são utilizados como forma de educação não-formal, sendo uma educação diferenciada em relação ao ensino tradicional obtido nas escolas. Contribuindo com essa reflexão Cardoso (2008, p. 23) afirma que:

\begin{abstract}
Cabe aos museus e centros de ciências, promover a divulgação científica sem cair no reducionismo e banalização dos conteúdos científicos e tecnológicos, gerando uma cultura científica que capacite os cidadãos a discursarem livremente sobre ciências, com o mínimo de noção de processos e implicações da ciência no cotidiano das pessoas, certamente é um desafio e uma atitude de responsabilidade social.
\end{abstract}

De acordo com Cazelli et al., (1997) os museus atualmente são classificados como ambientes de aprendizagem ativo, provocando dessa maneira uma interação social entre os visitantes, podendo provocar nos sujeitos que o visitam uma curiosidade epistemológica baseada em uma aprendizagem significativa (CAZELLI et al., 1999).

Faz-se necessário ressaltar que, neste estudo, selecionarmos o museu de zoologia como lócus da pesquisa, pois entendemos que este pode ser percebido como um espaço formativo para se trabalhar de maneira significativa o contexto da educação ambiental, tendo como parâmetro exemplares taxidermizados.

Os museus de ciências permitem a aproximação dos alunos com os aspectos ambientais, que provavelmente sem a ajuda deste espaço, não poderia ser observado e ensinado utilizando modelo "in vivo". Além de aproximar os estudantes ao meio acadêmico-científico, e podendo despertar o interesse para a área de Ciências Naturais, estimulando a formação de cidadãos comprometidos e responsáveis com o meio ambiente, a qual estão inseridos (MOREIRA, 2014). 
o museu de zoologia como espaço formativo: uma experiência que vale a pena ser vivenciada

A conservação de animais, colocando-os em museus didáticos e expositivos, auxilia um estudo in natura e in loco de espécies que de outra maneira se perderiam na natureza. Conservar e armazenar, é um recurso didático para professores de Educação Ambiental, Zoologia, Ecologia, Ciências e Biologia (TAFAREL, 2011).

No ambiente escolar formal, muitas ilustrações e outros recursos didáticos não demonstram a realidade dos organismos, portanto ambientes como museus de Ciências Naturais e exemplares taxidermizados podem apresentar a realidade das espécies (ACHUTTI, 2003).

Faz-se necessário ressaltar, que a finalidade do trabalho realizado pelo taxidermista visa manter as características e informações físicas do animal, de maneira muito fiel a realidade, a partir do conhecimento de áreas como biologia (ROCHA, 2012). A taxidermia é considerada como instrumento de estudo de diversas disciplinas, entre elas, biogeografia, ecologia, sistemática, anatomia, fisiologia e biologia da conservação (VON MATTER et al., 2010). Esta técnica é um grande aporte à pesquisa científica e a apropriação do conhecimento escolar (AURICCHIO; SALOMÃO, 2002).

Uma peça taxidermizada busca ser fiel à realidade, com o intuito de ser utilizada como um instrumento didático (ANDRADE; VICTÓRIO, 2015). Além dessa função, as coleções em que estes espécimes, serão destinados, podem ser de cunho zoológico, científico, ou ainda de uso da educação escolar (ROCHA, 2012). Neste sentido, a taxidermizada possibilita uma melhor visualização das características das espécies, antes vistas apenas em livros didáticos. A realização de processos educativos que se preocupam com a preservação, em especial a biodiversidade, devem buscar uma sensibilidade e sentimento de educação e responsabilidade dos indivíduos em relação ao meio ambiente (ABÍLIO; FLORENTINO; RUFFO, 2010).

Portanto, a utilização dos animais taxidermizados em ambientes como o museu possibilita uma aprendizagem mais dinâmica e contextualizada, pelo fato dos alunos estarem diante dos animais silvestres que eram só vistos em gravuras de livros didáticos, distanciando a sua realidade social do conhecimento cientifico (AURICCHIO; SALOMÃO, 2002). O sujeito que visita um museu para comparar e vivenciar o que lhe 
é passado dentro da sala de aula, tem a experiência de construir uma correlação entre o conhecimento teórico prático. Neste momento, de integração de saberes, ocorre a junção de informações em que os alunos agregam os conhecimentos prévios e assim a aprendizagem significativa é construída (AUSUBEL, 1963).

\section{Material e métodos}

A escolha do museu de zoologia como lócus da pesquisa se deu por entender que este é um ambiente propício para a transmissão de conhecimentos, uma vez que possui um espaço diferenciado e objetos com um conteúdo agregado (MARANDINO, 2008). Além desses elementos, a linguagem constitui um importante artifício na forma de textos e imagens apresentados em exposições. Para tanto, na mediação entre o conhecimento exposto e o público, é preciso que haja uma adequação da linguagem e do conteúdo, tornando-o esse, acessível para cada grupo de visitantes (MARANDINO, 2008).

Isso posto, o caminho metodológico está pautado nos princípios da pesquisa qualitativa, descritos por Lüdke e André (1986), que abordam cinco características básicas aqui sintetizadas: a pesquisa qualitativa tem o ambiente natural como sua fonte direta de dados e o pesquisador como seu principal instrumento; os dados coletados são predominantemente descritivos; a preocupação com o processo é muito maior do que com o produto; o significado que as pessoas dão às coisas e à sua vida são focos de atenção especial pelo pesquisador; e a análise dos dados tende a seguir um processo indutivo. (BOGDAN; BIKLEN, 1982).

O conjunto de procedimentos de apoio a investigação foi formado pela pesquisa bibliográfica e de campo. A pesquisa bibliográfica permitiu o aprofundamento e ampliação dos pressupostos teóricos de autores que discutem temas como: museu de zoologia, educação ambiental, formação de conceitos e animais taxidermizados.

Faz-se necessário ressaltar que a pesquisa bibliográfica permitiu o aprofundamento e ampliação dos pressupostos teóricos de autores que discutem a temática, objeto de estudo.

A pesquisa de campo foi realizada como forma de obter as informações junto aos alunos dos anos finais do ensino fundamental de uma escola pública, localizada na 
$\underline{\text { o museu de zoologia como espaço formativo: uma experiência que vale a pena ser vivenciada }}$ cidade de Londrina. Para garantir o anonimato dos estudantes utilizaremos para identifica-los a letra A significando aluno, seguida de número ordinário.

Para tanto, a pesquisa de campo foi realizada no museu de Zoologia, localizado no Centro de Ciências Biológicas da Universidade Estadual de Londrina, onde foram expostos alguns animais taxidermizados representantes da fauna brasileira de diversos Biomas que possuímos. A exposição foi organizada dividindo os animais por Biomas brasileiros, e em seguida foi trabalhado com os alunos sobre os animais endêmicos, e a sua importância para a preservação da fauna e flora de cada Bioma, além dos animais que realizam a transição de ambientes. 0 percurso que elaboramos teve como finalidade demonstrar a riqueza da biodiversidade que possuímos no Brasil, bem como, que os alunos entendessem o valor imprescindível da conservação da fauna e da flora.

\section{Resultados e discussões}

Ao iniciar as atividades no Museu de Zoologia, foi entregue aos alunos um questionário com 9 questões sobre a fauna e flora e conhecimentos para a preservação do meio ambiente. As perguntas foram distribuídas para 16 alunos com idades entre onze a quatorze anos. A primeira questão apresentou os seguintes questionamentos: Você gosta de animais? Você acha que os animais são importantes para o meio ambiente?

As respostas foram muito interessantes, pois todos os dezesseis alunos responderam afirmando que os animais são importantes para o meio ambiente, como veremos nas falas abaixo:

Eu acho que sim, pois os animais ajudam muito na natureza, em várias áreas, exemplo as abelhas que produzem mel $e$ polinizam o ambiente (A, 12).

Sim, para manter o equilíbrio da cadeia alimentar e ajudar no meio ambiente para mantê-lo corretamente (A, 3).

Quando perguntado aos alunos se os mesmos já tinham ouvido falar sobre espécies endêmicas? Os mesmos responderam que não. Diante disso, foi trabalhado o conceito das espécies endêmicas relacionando este com o cotidiano vivenciado pelos alunos. Faz-se necessário ressaltar que é imprescindível relacionar o conhecimento do 
senso comum e cientifico, por isso levar em consideração o que o aluno sabe a partir de suas experiências torna o aprendizado mais significativo e essa ação se dá por meio da mediação.

Portanto, por meio das relações mediadas que o sujeito se apropria da cultura. A atividade humana pressupõe o uso de instrumentos psicológicos, os quais assumem um caráter mediador nas relações desenvolvidas por cada indivíduo. Todas as funções psíquicas superiores têm como traço comum o fato de serem processos mediados. A relação do homem com o mundo não é direta, e sim uma relação mediada. Este processo acontece por meio de elementos mediadores externos, ou seja, instrumentos e signos da cultura que se interpõem entre o sujeito e o objeto. Com relação a isso, Vigotsky (2007, p. 27) explicita que "a presença de elementos mediadores introduz um elo a mais nas relações psicológicas." Eles são essenciais para o desempenho das funções mentais, tornando possíveis atividades voluntárias e intencionais, controladas pelo próprio indivíduo.

Sendo assim, a mediação pedagógica enriquece as interações que o sujeito estabelece com os seus pares, contribuindo para que ele desenvolva e amplie seu repertório de conhecimentos e de cultura. É por essa lógica que Vigotski por exemplo afirma que "aquilo que é zona de desenvolvimento proximal hoje será o nível de desenvolvimento real amanhã, ou seja, aquilo que uma criança pode fazer com assistência hoje, ela será capaz de fazer sozinha amanhã." (REGO, 2011, p. 74).

Entendendo a formação dos alunos por este viés, neste estudo trabalhamos as questões relacionadas ao meio ambiente de maneira contextualizada, assumindo assim, a função de mediador do conhecimento, motivando os alunos a participarem do encontro formativo realizado no Museu de Zoologia, de forma crítica e reflexiva.

Foi perguntado aos alunos se estes, já tinham tido contato com animais silvestres, e se gostavam de estudar sobre o assunto? Todos disseram que sim. Segundo os alunos, estudar apenas por livros não atraía muita curiosidade, porém se pudessem ver os animais próximos o aprendizado seria muito mais significativo. Esta resposta veio ao encontro da proposta da nossa pesquisa, pois possibilitar aos alunos vivenciar o conteúdo trabalhado podendo articular teoria e pratica propicia um aprendizado mais significativo, despertando assim, a curiosidade e o respeito pelo meio ambiente. 
o museu de zoologia como espaço formativo: uma experiência que vale a pena ser vivenciada

Corroborando com essa reflexão, Smolka (2000) reitera que o aluno aprende de uma forma mais efetiva quando participa de atividades coletivas que tenham sentido para ele e nas quais sua atuação seja assistida e mediada por alguém que tenha consciência da importância do processo de ensino e aprendizagem e seja capaz de instrumentalizá-lo de maneira apropriada. Na sua ótica, nós não reagimos imediatamente a estímulos, pois o nosso comportamento é semiticamente mediado, respondendo a significados que atribuímos a situações, cuja interpretação depende de um contexto cultural e social.

Essa relação semiótica está presente, tanto nas origens sociais das funções mentais superiores, como nas práticas da cultura. Ela pode ser verificada também no papel desempenhado por pais e mestres quando dão oportunidades ao sujeito para compartilhar estas práticas e, através delas, apropriar-se gradualmente das funções mentais por meio da demonstração, da participação guiada e das tarefas que envolvam uma relação verbal. As ferramentas de que o ser humano dispõe nesse momento para agir não são apenas materiais, elas são essencialmente simbólicas como a fala, a escrita, o conhecimento, valores, crenças etc., que irão mediar a sua relação com o mundo (COELHO, 2011, p. 62).

Para tanto, no desenrolar do estudo em questão percebemos que os alunos se foram se apropriando do conhecimento, na medida que em que o grupo foi trocando experiências e aprendizagens a respeito da temática meio ambiente tendo como foco os animais taxidermizado. Ainda que todos receberam as mesmas informações, alguns alunos apresentaram mais facilidade na compreensão e, portanto, exerceram um papel de colaboradores durante a aula ministrada.

Outra pergunta que teve a resposta "não" como unanimidade, foi a respeito se eles tinham o conhecimento do que era a técnica de taxidermia e se já tinham visto algum animal taxidermizado, ou seja, os alunos falaram que não conheciam e ficaram curiosos de como era feita esta técnica.

Diante disso, explicamos o funcionamento das técnicas, e como chegam esses animais no Museu de Zoologia da universidade. Em seguida trabalhamos o nome comum e científico dos animais, além do habitat e história natural de cada um ali presente. 
Os alunos ficaram encantados com os animais taxidermizado e perguntaram se a onça pintada é a mesma coisa que a onça parda? Foi respondido que são espécies diferentes, podendo estar na mesma região, porém com comportamentos diferentes, além de que a onça-pintada pode atingir até $2.75 \mathrm{~m}$ de cumprimento e mais de $150 \mathrm{~kg}$ sendo maior e mais pesada que a onça-parda. A onça-pintada é o único representante do gênero Panthera existente no hemisfério ocidental (ASTETE PEREZ, 2008).

Outro animal que chamou atenção dos alunos foram as serpentes taxidermizadas, provocando os seguintes questionamentos: Todas as serpentes são venenosas? As serpentes são malvadas? 0 que fazer quando encontrar uma serpente?

Em decorrência das questões foi ressaltado que todas as serpentes apresentam uma função venenosa, o que diferencia é a capacidade da inoculação secretado por glândulas salivares especializadas. Deste modo apenas algumas serpentes são peçonhentas, pois possuem uma dentição especializada para inocular o veneno (SANDRIN; PURTO; NARDI, 2016).

Abordamos também que as serpentes não são malvadas, o que acontece são acidentes, principalmente pelo fato da alta degradação do ambiente ocasionando o contato entre o ser humano e as serpentes, que nesses casos de encontro, o que deve ser feito é deixar o animal e não tentar a captura ou mexer com o animal, evitando mata-lo, pois são animais fundamentais para o equilíbrio do meio ambiente.

Ao final de todas essas perguntas, percebemos que o trabalho realizado no museu zoológico com auxílio de animais taxidermizados obteve um resultado satisfatório, ou seja, houve interação entre os participantes deste estudo o que gerou muitas discussões sobre o tema acerca da educação ambiental e os alunos ressaltaram que:

Estamos invadindo e destruindo a natureza (A, 8).

Os animais estão fazendo sua parte, chegou a hora de proteger eles e a casa deles (A, 2).

Temos que ser mais educados com o meio ambiente $(\mathrm{A}, 1)$.

Diante destas falas podemos perceber que por meio desse trabalho os alunos construíram uma visão mais humanizada e crítica acerca da educação ambiental. Nesse sentido, o museu enquanto lócus formativo se constituiu num espaço propício 
o museu de zoologia como espaço formativo: uma experiência que vale a pena ser vivenciada para estabelecer uma relação entre o conhecimento do senso comum e o conhecimento científico.

É importante ressaltar que, na concepção vigotskiana, a apropriação do conhecimento científico não acontece de forma alienada. 0 autor afirma que, por meio dos processos educacionais, podem-se formar sujeitos que questionem a contradição presente na realidade concreta. Nesta lógica, Duarte e Melo (2013, p. 341) aponta que:

[...] toda vez que um ser humano é impedido de apropriar-se daquilo que faça parte da riqueza do gênero humano, estamos perante um processo de alienação, um processo que impede a humanização desse indivíduo.

Portanto, o Museu Zoológico pode se constituir como espaço formativo, onde o saber é socializado tendo como parâmetro a relação entre conteúdo e realidade social, possibilitando dessa maneira uma práxis pedagógica.

\section{Considerações Finais}

A partir desta investigação, foi possível refletir sobre diversos aspectos que perpassam o contexto educativo, especialmente no que tange a importância da mediação envolvendo sujeito e conhecimento, neste caso entre pesquisador e alunos dos anos finais do ensino fundamental.

Atualmente, é comum conceber a mediação como um "termo plural", existindo conceitos de mediação e de mediador em diferentes áreas do conhecimento. Dessa forma, a ação mediadora não está restrita a uma categoria profissional ou a uma atividade específica. De acordo com Vigotsky (2007), a mediação pode ser classificada com base nas áreas das ciências da informação e da comunicação, distinguindo entre mediação midiática, que se desenvolve no universo das mídias, alocando o jornalista em posição de mediador; mediação cultural, a qual evidencia uma dimensão representativa, estética de diversas formas de artes e cultura em geral; e mediação pedagógica que, por sua vez, destaca a posição do docente como mediador, sendo ele responsável pelas interações educativas no processo de ensino e de aprendizagem. 
Como se nota, a palavra mediação pode gerar discussões diversas, evocando diferentes enfoques. Um desses enfoques remete à abordagem histórico-cultural, para a qual os elementos de mediação são aqueles que, ao serem interpostos entre dois polos de um processo, permitem que um seja incorporado ao outro, sem que nenhum deles perca suas características essenciais. As observações de Vigotski para a elucidação da categoria da mediação consideram as relações mediadas como indispensáveis para o desenvolvimento humano.

No âmbito da educação escolarizada, as relações de mediação refletem-se diretamente nas intervenções pedagógicas e, concomitantemente, na própria construção do conhecimento. Nesse processo de interação, o professor tem uma função imprescindível no que se refere às relações mediadas. Seu conhecimento e a sua consciência a respeito do processo de ensino e de aprendizagem possibilita o intercâmbio entre o ensinar e o aprender, entre o sujeito e o objeto do conhecimento. É nesse sentido que a mediação, à medida que favorece a interação entre pessoa e objeto do conhecimento, promove relações válidas de aprendizagem, propiciando, ao mesmo tempo, a reconstrução do saber e o desenvolvimento da subjetividade de cada sujeito, tendo como parâmetro o saber escolar e a realidade social.

Nessa perspectiva, queremos destacar ainda que, de acordo com Abílio, Florentino e Ruffo (2010), articular os conteúdos escolares com a realidade e os interesses dos alunos é uma premissa para que tenhamos um ensino comprometido e significativo, e isso ficou claro quando os alunos refletiram acerca de conceitos de conservação ambiental e biodiversidade tendo como parâmetro alguns animais taxidermizados representantes da fauna brasileira de diversos Biomas que possuímos.

As reflexões despertadas, neste contexto, apontaram novas questões e hipóteses que necessitam ser investigadas, tais como pensar o Museu de Zoologia como um espaço educativo e formativo, podendo assim, a possibilitar os aprendizes a pensar na transformação da natureza e da sociedade, entendendo essa transformação, num primeiro momento, como a mudança do próprio pensamento humano no que tange aos cuidados com o meio ambiente.

Isso posto, o estudo nos provocou a pensar, que os museus de zoologia permitem a aproximação dos alunos com os aspectos ambientais, que provavelmente sem a ajuda deste espaço, não poderia ser observado e ensinado utilizando modelo "in vivo", além de aproximar os estudantes ao meio acadêmico-científico, e podendo 
$\underline{\text { o museu de zoologia como espaço formativo: uma experiência que vale a pena ser vivenciada }}$ despertar o interesse para a área de Ciências Naturais, estimulando a formação de cidadãos comprometidos e responsáveis com o meio ambiente, a qual estão inseridos, podendo assim, pensar na transformação da natureza e da sociedade, entendendo essa transformação, num primeiro momento, como a mudança do próprio pensamento humano no que tange aos cuidados com o meio ambiente.

Para tanto, temos que pensar o museu como linguagem de mediação entre o conhecimento do senso comum e cientifico, ou seja, pensando no contexto social, político, econômico, cultural e ambiental da sociedade contemporânea, pode-se perceber por meio da pesquisa, que o ensino em ciências, atualmente, não pode ser efetivado utilizando-se somente de recursos expositivos, geralmente empregados no ambiente escolar.

Com isso, os espaços como o museu de zoologia, por exemplo, estão sendo muito valorizados no que diz ao processo de ensino e aprendizagem, pois possibilita a apropriação do conhecimento de maneira significativa, articulando a teoria e a prática.

Sendo assim, a sociedade de hoje necessita da contribuição holística das diversas áreas do conhecimento para que ocorra uma reflexão da ação da problemática socioambiental.

A formação de uma nova sociedade, ecologicamente correta e sustentável, é o ponto de partida na construção de cidadãos voltados para o bem comum, de ações de curto a longo prazo, para todos os habitantes deste planeta. Na adequação de uma população mais adaptada às novas realidades, a educação tem papel-chave como meio de transformação.

Destarte, neste estudo os alunos por meio das ações realizadas apresentaram interesse em conhecer as relações entre o homem e a natureza e este interesse pode passar pelo campo da sensibilização, ou seja, entendemos que a sensibilização dos alunos no ambiente escolar gera iniciativas que ultrapassa o ambiente escolar, formando um aluno cidadão e mais comprometido com o meio ambiente. Para tanto, o uso de museus com animais taxidermizados empregado no presente trabalho é eficiente para o conhecimento, e proporciona ao educando um contato direto com o objeto de estudo conduzindo a um maior interesse sobre o tema apresentado. 


\section{Referências}

ABÍLIO, Francisco José Pegado; FLORENTINO, Hugo da Silva; RUFFO, Thiago Leite de Melo. Educação ambiental no bioma caatinga: formação continuada de professores de escolas públicas de São João do Cariri, Paraíba. Pesquisa em Educação Ambiental, São Paulo, v. 5, n. 1, p. 171-193, 2010.

ACHUTTI, Luiz Eduardo Robinson. Fotos e palavras, do campo aos livros. Studium, Campinas, n. 12, p. 5-16, 2003.

ANDRADE, Luciana Paes; VICTÓRIO, Cristiane Fratini. Proposta de criação de uma coleção de vertebrados taxidermizados como modelo para atividades de ensino. Revista de Ensino, Educação e Ciências Humanas, Londrina, v. 16, n. 5, p. 479-482, 2015.

ASTETE PEREZ, Samuel Henrique. Ecologia da onça-pintada nos parques nacionais Serra da Capivara e Serra das Confusões, Piauí. 2008. Dissertação (Mestrado em biologia animal) - Universidade de Brasília, Brasília, 2008.

AURICCHIO, Paulo; SALOMÃO, Maria da Graça. Técnicas de coleta e preparação de vertebrados para fins científicos e didáticos. São Paulo: Instituto Pau Brasil de História Natural, 2002.

AUSUBEL, David P. The psychology of meaningful verbal learning. [S. l.]: Grune \& Stratton, 1963.

BOGDAN, Robert; BIKLEN, Sari. Investigação qualitativa em educação: uma introdução à teoria e aos métodos. Portugal: Porto, 1982.

CARDOSO, Rafael. Design para um mundo complexo. São Paulo: Cosac e Naify, 2008.

CAZELLI, Sibele et al. Padrões de interação e aprendizagem compartilhada na exposição laboratório de astronomia. Revista Brasileira de Estudos Pedagógicos, Brasília, v. 78, n. 188-190, p. 413-471, 1997.

CAZELLI, Sibele et al. Tendências pedagógicas das exposições de um museu de ciência. In: ENCONTRO NACIONAL DE PESQUISA EM EDUCAÇÃO EM CIÊNCIAS, 2., 1999, Valinhos. Anais [...]. Valinhos: ENPEC, 1999. v. 2, p. 1-12.

COELHO, Teixeira. Cultura e educação. São Paulo: Iluminuras e Itaú Cultural, 2011.

DUARTE, Adriana; MELO, Savana Diniz Gomes. Qualidade da educação e política de remuneração docente: quais as implicações dessa relação?. Revista Educação em Questão, Natal, v. 46, n. 32, 2013.

FREIRE. P. Pedagogia da esperança: um reencontro com a pedagogia do oprimido. Rio de Janeiro: Paz e Terra, 1992.

LÜDKE, Menga; ANDRÉ, Marli. Pesquisa em educação: abordagens qualitativas. São Paulo: E. P. U., 1986. 
o museu de zoologia como espaço formativo: uma experiência que vale a pena ser vivenciada

MARANDINO Marta. Museus de ciências como espaços de educação: In: Museus: dos gabinetes de curiosidades à museologia moderna. Belo Horizonte: Argumentum, 2005, p. 165-176.

MARANDINO, Martha. Educação em museus: a mediação em foco. São Paulo: Geenf/FEUSP, 2008.

MOREIRA, Jasmine Cardozo. Geoturismo e interpretação ambiental. Ponta Grossa: Editora UEPG, 2014.

REGO, Teresa Cristina. Vygotsky: uma perspectiva histórico-cultural da educação. Petrópolis: Vozes, 2011.

ROCHA, Eduardo Venâncio. Educação ambiental com o auxílio de animais taxidermizados do bioma cerrado: formação continuada de professores que trabalham com pessoas cegas e de baixa visão. 2012. Dissertação (Mestrado em ciências humanas) - Universidade Federal de Uberlândia, Uberlândia, 2012.

SANDRIN, Maria de Fátima Neves; PUORTO, Giuseppe; NARDI, Roberto. Serpentes e acidentes ofídicos: um estudo sobre erros conceituais em livros didáticos. Investigações em ensino de ciências, Porto Alegre, v. 10, n. 3, p. 281-298, 2016.

SMOLKA, Ana Luiza Bustamante.. 0 impróprio e o impertinente na apropriação das práticas sociais. Cadernos Cedes, Campinas, v. 20, n. 50, p. 26-40, 2000.

TAFFAREL, Carlos Domingos. Museus escolares: a utilização de técnicas de taxidermia como auxílio no ensino da educação ambiental. 2011. Monografia (Especialização em educação ambiental) - Universidade Federal de Santa Maria, Santa Maria, 2011.

VASCONCELOS, Simão Dias; SOUTO, Emanuel. O livro didático de ciências no ensino fundamental proposta de critérios para análise do conteúdo zoológico. Ciências \& Educação, Bauru, v. 9, n. 1, p. 93-104, 2003.

VIGOTSKY, L. S. A formação social da mente. Tradução de José Cipolla Neto, Luís Silveira Menna Barreto e Solange Castro Afeche. 7. ed. São Paulo: Martins Fontes, 2007.

VON MATTER, Sandro et al. (org.). Ornitologia e conservação: ciência aplicada, técnicas de pesquisa e levantamento. Rio de Janeiro: Technical Books Editora, 2010.

Recebido em: 03 nov. 2020 Aceite em: 28 dez. 2020 